\title{
Knowledge and attitudes towards breast cancer among women in Rombo district, Kilimanjaro region
}

\author{
Gudilla Valentine MD5
}

\begin{abstract}
Objective: To assess knowledge and attitudes towards breast cancer among women aged 30 years and above in Rombo district Kilimanjaro region.
\end{abstract}

Design: A descriptive,cross- sectional study

Setting: Rombo district, Kilimanjaro region, Tanzania.

Results: Of the 150 women who participated in the study, 64.7\% had either never been to school or not completed primary school. 17(11.3\%) had knowledge on the presenting features of breast cancer at early stages of the disease.

About $11 \%$ knew at least one of the predisposing factors of breast cancer while $89 \%$ knew nothing on it. Fifty percent were in dilemma on whether one can detect lumps (mass on breast) at home, 33. $3^{\prime} \%$ said it can not be done at home while $16.7 \%$ knew it can be done at home.

$53 \%$ could not tell whether breast cancer is curable or not, $28 \%$ said it is incurable while $19 \%$ knew it is curable if detected early. For those who claimed it is not curable, their reasons were curse (24\%), most of the patients died (31\%) and once one gets it must kill her (45\%).

Recommendation: The findings show that there is a need to educate the community on breast cancer.

\section{INTRODUCTION}

Breast cancer is a malignant neoplasm mostly affecting women all over the world. It is the second only to cervical cancer as a cause of death from cancer among women [1]. The common group affected is women above 30 years of age, the mean and median age being 60 and 61 years respectively [1]

The risk factors of breast cancer include: genetic predisposition, where $85 \%$ of women with breast cancer have been found to have mutation at BRCA1-gene found on chromosome 17, Mutations at BRCA 2 and P53 have also been noted [1]. Nulliparous women and women whose full-term pregnancy was after 35 years of age have 1.5 times higher risk than multiparous women.

Early menarche (under 12years) and late natural menopause seem to be high risk factors. When associated with proliferative changes, pappilloma or atypical epithelial hyperplasia fibrocystic disease can develop breast cancer. Women with uterine cancer have been found to have increased risk of breast cancer as well as increasing age [1].
Incidence rates are similar in blacks and whites in the age group 40-44 year and higher incidence rates are observed in black women in younger age groups (below age 40)[2]. Age is a strong indicator for increased risk of breast cancer. [2] Exposure to environmental oestrogen e.g. due to pollution with DDT, use of oral contraceptive and hormonal therapy in post menopausal are also risk factors. [1] Moreover the association of breast cancer with HIV /AIDS is still debatable, some say there is association of breast cancer with HIV/AIDS [3], while others say the association is not clear [4]. Also breast cancer has been associated with the virus called Mouse mammary tumour virus (MMTV) [5]

Breast cancer can be treated if detected at early stage but most of the patients come to physicians late when the complications have arisen and so difficult to treat. Early detection is achieved only if the community is aware of the techniques used in assessment of the breast for cancer. Breast cancer manifests as painless palpable mass thus makes women notice the disease very late [6]. Other manifestation include, breast deformity, nipple discharge, skin ulceration, erythema, itching and occasional blood discharge [6]. The lump is hard, painless, 
irregular and fixed. In its late stage, bone pain, dyspnoea and meningism syndrome are characteristic of breast cancer [6].

Ten-year age groups distribution showed that $4.7 \%$ were below 30 years of age, 16.1 $\%$ were $30-39$ years, $28.3 \%$ were $40-49$ years, $26.3 \%$ were $50-59$ years, $16.9 \%$ were $60-69$ years, $6.1 \%$ were $70-79$ years and I.M/o were 80 years of age or older in Lebanon [7].

Cost and access barriers are shared by lowincome women from various ethnic and racial groups, as is a purported lack of physician referral.

A study, conducted by the Cancer Education Division of the University of Colorado Cancer Centre, has been to determine the attitudes and practices among health care providers in areas of Colorado with relatively large Hispanic populations (concerning screening mammography, clinical breast examination, breast self-examination, and Pap testing) and to design interventions to address any deficiencies or problems recognized. They concluded that Educational approaches to primary care professionals may improve the effectiveness of breast and cervical cancer screening, although a variety of other approaches will also be necessary to decrease barriers to screening of Hispanic women [8]

In Iran, Seventy-five percent of the women had knowledge on breast cancer, but only $27 \%$ knew that breast pain is not a symptom of breast cancer. Although $73 \%$ of women knew that contact with a relative with breast cancer could not lead to development of breast cancer, the respondents' knowledge of risk factors of breast cancer was not satisfactory. With regard to women's attitudes toward Breast Self Examination (BSE), the majority believed that it is not difficult and time consuming or troublesome $(63 \%$ and $72 \%$, respectively). Sixty-three percent of the respondents claimed that they knew how to examine their breasts, but only $6 \%$ performed BSE monthly. The practice of BSE was significantly associated with age, the level of education, personal history of breast problems, and knowledge of how to examine the breast.

The sample showed strong belief in nipple discharge as a causative factor of breast cancer and had significant correlation and BSE practice in USA. [9]

In Tanzania a little is known about carcinoma of breast which is now increasing tremendously. In ORCI the data show that, cancer ranks number two after uterine cancer in Tanzania [10] Diagnosis of breast cancer in Tanzania is made late and most of the times already ulcerating. This is due to poor health education to most mothers [10]

Currently, in Tanzania, MEWATA is doing their level best to tackle breast cancer. About 100 women physicians and 7250 women were educated on risk factors, BSE and generally on breast cancer in Dar-esSalaam. Out of 7250 who were examined $757(10.4 \%)$ were suspected to have breast cancer . The end results were: 481 umps, 34 had breast cancer, II had cyst, and 3 had other problems after doing FNAC [MEWATA personal communication].

This study will measure knowledge and attitude of the community of Tanzania especially in rural areas where level of education is low so that intervention is planned well.

\section{METHODOLOGY}

A descriptive cross-sectional study was done at Nanjara-Rcha ward in Rombo district of Kilimanjaro region. The study was conducted on women aged 30 years and above using multistage sampling technique. The sample size calculated was 150. Permission sought from the appropriate authorities. The study population was interviewed through standard questionnaires after household visits. Analysis was done through Epi-info 6 version software.

Consent was sought from the participants and they were assured of confidentiality of the information between the interviewee and the interviewer. 
Two women refused to participate in the study for reasons that could not be established.

\section{RESULTS}

1. SIGNS AND SYMPTOMS OF BREAST CANCER THAT WERE KNOWN

\begin{tabular}{|c|c|c|}
\hline $\begin{array}{l}\text { No. of } \\
\text { symptoms } \\
\text { and signs }\end{array}$ & Frequency & Percent \\
\hline 0 & 97 & $64.7 \%$ \\
\hline 1 & 19 & $12.7 \%$ \\
\hline 2 & 17 & $11.3 \%$ \\
\hline$>2$ & 17 & $11.3 \%$ \\
\hline Total & 150 & $100 \%$ \\
\hline
\end{tabular}

Almost $65 \%$ could not mention any of the features of presentation of breast cancer at early Stage

3. PREDISPOSING FACTORS ASSOCIATED WITH BREAST CANCER THAT WERE KNOWN

\begin{tabular}{|l|l|}
$\begin{array}{l}\text { Predisposing } \\
\text { factors }\end{array}$ & Frequency \\
\hline 0 & 137 \\
\hline 1 & 12 \\
\hline 2 & 1 \\
\hline$>2$ & 2 \\
\hline Total & 150 \\
\hline
\end{tabular}

Only 16 out of 150 women assessed $(10.7 \%)$ could mention at least one of the predisposing factors associated with breast cancer.

3. OPINION ON WHETHER THEY THOUGHT BREAST CANCERR COULD BE DETECTED AT HOME

\begin{tabular}{|l|l|}
\hline Response & Frequency \\
\hline Yes & 25 \\
\hline No & 50 \\
\hline I do not know & 75 \\
\hline Total & 150 \\
\hline
\end{tabular}

$50 \%$ of participants could not tell whether breast cancer can be detected at home. Only $16.7 \%$ knew it can be detected.
4. BREAST CANCER DETECTION METHODS KNOWN

\begin{tabular}{|c|c|}
\hline Method & Frequency \\
\hline $\begin{array}{l}\text { Comparing } \\
\text { levels of } \\
\text { nipples }\end{array}$ & 6 \\
\hline $\begin{array}{l}\text { Palpation } \\
\text { of lumps } \\
\text { when } \\
\text { bathing }\end{array}$ & 3 \\
\hline $\begin{array}{l}\text { Comparing } \\
\text { size and } \\
\text { shape of } \\
\text { breast }\end{array}$ & 11 \\
\hline Total & 22 \\
\hline
\end{tabular}

Only 22 women could mention at least one detection method of breast cancer.

4. RESPONSES ON WHETHER BREAST CANCER COULD BE CURED

\begin{tabular}{|l|l|}
\hline Response & Frequency \\
\hline Yes & 29 \\
\hline No & 42 \\
\hline I do not know & 79 \\
\hline Total & 150 \\
\hline
\end{tabular}

Only $19.3 \%$ of those assessed said that breast cancer can be cured.

6. REASONS AS TO 'WHY SOME WOMEN THOUGHT BREAST CANCER COULD NOT BE CURED

\begin{tabular}{|l|l|}
\hline $\begin{array}{l}\text { Response } \\
\text { Curse }\end{array}$ & Frequency \\
\hline $\begin{array}{l}\text { Most patients } \\
\text { die }\end{array}$ & 13 \\
\hline $\begin{array}{l}\text { Must die } \\
\text { Total }\end{array}$ & 19 \\
\hline
\end{tabular}

Of those who said breast cancer is not cured, most of them said once you get it you must die.

\section{DISCUSSION}

The study was conducted on 150 women aged 30years and above amongst them $85 \%$ were $30-59$ years. About $65 \%$ had either never been to school or got incomplete primary school education.

The occupation of these women could not give any clue as to association with the knowledge and attitude towards breast cancer. 
All women interviewed said they have heard of breast cancer before though $65 \%$ failed to mention at least one of the features suggestive of breast cancer at an early stage.

About $13 \%$ mentioned only one of the features, two features by $11 \%$ and more than two by $11 \%$. This is very different from the study done in Iran where $75 \%$ of women had knowledge on breast cancer. Twelve percent of women who participated in the study could mention at least one predisposing factors while rest cold not. Obesity and the use of cholesterol foods were reported with high frequency followed by genetic factors for the reasons that could not be established.

About $17 \%$ of women said that breast cancer can be detected by self examination at home while thirty percent were in dilemma. $33 \%$ said it is impossible to detect breast cancer at home because of the reasons that included curse $30.8 \%$, almost all those who got the disease died so one is very likely to die (33.3\%) and $35.9 \%$ believed that who ever gets the disease must die for the reasons they could not say. This shows that these people have poor attitude towards the disease although all of them said they could advise a friend with breast cancer to go to the hospital for treatment after giving them little knowledge on breast cancer. On the other hand going to the hospital was seen as a routine or may be as a way to counsel the victim in the community.
Among those who said it can be detected at home; they succeeded to mention presence of lumps and comparison of the level of nipples when standing before a mirror as methods of detection.

Thirteen of them could mention at least two methods of detection of breast cancer meaning the rest knew nothing. With regard to treatment; 29 women $(19.3 \%)$ said it can be cured, 28\%) said it is incurable while more than fifty percent (i.e. $52.7 \%$ ) could not tell whether it is curable or not.

\section{CONCLUSION}

Generally, the study population had very little knowledge and poor attitude towards breast cancer probably because of the low level of education they have and also lack of information about health issues since the place is a remote area.

\section{RECOMMENDATIONS}

1. Health education should be promoted in rural areas so that people can become aware of their health problems.

2. Since most of people in rural areas hardly go for secondary education, at least an overview of breast cancer should be in the curriculum of primary schools especially for girls.

3. If possible breast self examination should be integrated in the existing health programs.

\section{References not provided!}

